\title{
Relugolix: New 0ral Gonadotropin-Releasing Hormone (GnRH) Antagonist
}

\author{
Atsushi Imai*, Hazuki Kagawa, Satoshi Ichigo, Hiroshi Takagi, Kazutoshi Matsunami and Masashi \\ Hori \\ Department of Obstetrics and Gynecology, Matsunami General Hospital, Japan \\ *Corresponding author: Atsushi Imai, MD, PhD, Department of Obstetrics and Gynecology, Matsunami General \\ Hospital, Japan
}

\begin{tabular}{|c|c|}
\hline ARTICLE INFO & ABSTRACT \\
\hline Received: 崑 May 15, 2019 & With the recent development of Gonadotropin-Releasing Hormone (GnRH) analogs, \\
\hline Published: 慧 June 03, 2019 & $\begin{array}{l}\text { physicians have manipulated gonadotropin secretion and, consequently, to treat sex } \\
\text { steroid-dependent hormonal disorders such as central precocious puberty in children, }\end{array}$ \\
\hline $\begin{array}{l}\text { Citation: Atsushi I, Hazuki K, Satoshi } \\
\text { I, Hiroshi T, Kazutoshi M, Masashi H. } \\
\text { Relugolix: New 0ral Gonadotropin-Re- } \\
\text { leasing Hormone (GnRH) Antagonist. } \\
\text { Biomed J Sci \& Tech Res 18(3)-2019. } \\
\text { BJSTR. MS.ID.003169. }\end{array}$ & $\begin{array}{l}\text { and benign prostatic hypertrophy and prostate cancer in men, and endometriosis, } \\
\text { leiomyoma and breast cancer in women. GnRH agonists can cause transient } \\
\text { deterioration of clinical symptoms associated with an initial surge of gonadotropins } \\
\text { and gonadal hormones. However, the peptide antagonists must be administered by } \\
\text { frequent subcutaneous injection or sustained release formulation due to orally fragile } \\
\text { bioavailability. A new oral nonpeptide GnRH antagonist, relugolix, promptly lowers } \\
\text { pituitary gonadotropin by GnRH receptor competition lowering estrogen level in women }\end{array}$ \\
\hline $\begin{array}{l}\text { Keywords: Gonadotropin-Releasing Hor- } \\
\text { mone Antagonist; Orally Active Nonpeptide } \\
\text { Formula; Uterine Myoma; Dysfunctional } \\
\text { Uterine Bleeding: Hormone-Dependent }\end{array}$ & $\begin{array}{l}\text { and testosterone in men within a few days without the symptom flare-up observed with } \\
\text { GnRH agonist. Sex steroid levels to baseline and menses resumed more quickly after the } \\
\text { oral GnRH antagonist withdrawal. The oral GnRH antagonist may play an ideal role in } \\
\text { therapeutic management of the estrogen or androgen-dependent disorders. }\end{array}$ \\
\hline
\end{tabular}
Disorder

\section{Introduction}

The decapeptide hormone, Gonadotropin-Releasing Hormone (GnRH), induces gonadotropins (luteinizing hormone and folliclestimulating hormone) secretion from the anterior pituitary in an orderly way which is important for the control of gonadal function and normal ovarian cyclicity. The action of GnRH is mediated by its binding to high affinity membrane receptors belonging to the seven-transmembrane receptor family. It is noted that sustained occupancy of the receptor with GnRH itself or a GnRH agonist caused desensitization. The GnRH agonist-induced downregulation has been applied to manipulate gonadotropin secretion and, consequently, to treat sex steroid (estrogen or androgen)dependent hormonal disorders such as central precocious puberty in children, and benign prostatic hypertrophy and prostate cancer in men, and endometriosis, leiomyoma and breast cancer in women [1-4].

However, GnRH agonists can cause transient worse clinical symptoms associated with an initial surge of gonadotropins and gonadal hormones [1-4]. GnRH antagonists, in contrast to GnRH agonists, achieve an immediate reduction of theses hormones and thus fast onset of therapeutic effects without undesirable adverse events induced by the flare-up. To data, several peptide GnRH antagonists have been developed, including cetrorelix [5,6] and ganirelix for in vitro fertilization [7,8], and degarelix for advanced prostate cancer $[9,10]$. These peptide antagonists, however, had to be administered by frequent subcutaneous injection or sustained release formulation due to orally fragile bioavailability.

Many nonpeptide GnRH antagonists have been developed by several research groups. Relugolix (Relumina $($ ), an oral nonpeptide GnRH receptor antagonist, promptly suppresses pituitary gonadotropin by GnRH receptor competition, lowering sex steroids levels within a few days, without the symptom flareup associated with GnRH agonist [11-13]. More recently, Osuga et al. [14] demonstrated the noninferiority of relugolix compared with current GnRH analogs in reducing heavy menstrual bleeding associated with uterine leiomyoma. This novel oral GnRH antagonist showed a rapid effect on the symptoms and reduced the leiomyoma and uterine volumes. Depot preparation of GnRH agonists also reduce leiomyoma size but have a delayed onset and must be given by monthly injection. Once daily oral intake achieved a similar proportion of heavy menstrual bleeding responders at 6-12 weeks. 
MacLean et al. [15] investigated relugolix effect on serum testosterone level in healthy volunteers as a possible prostate cancer treatment. The oral GnRH antagonist produced sustained reduction in testosterone level to below castrate level. Testosterone flare-up did not occur. The GnRH antagonist are an ideal option for testosterone suppression in benign prostate hypertrophy and prostate cancer. The attractive advantages of orally available $\mathrm{GnRH}$ antagonists over peptide antagonists includes the rapid recovery of gonadal function after drug withdrawal, since peptide antagonists are usually administered by subcutaneous injection in sustained release preparation and are unable to be discontinued during the release period even when undesirable adverse events occur.

Discontinuation after 28-day oral administration resulted in recovery of female reproductive function from a completely suppressed state in approximately 5 days, followed by continuous estrous phase for several days. The oral GnRH antagonist may play an ideal role in therapeutic management of the estrogen or androgen-dependent disorders.; e.g. endometriosis, uterine myomas, hirsutism, dysfunctional uterine bleeding, premenstrual syndrome, precocious puberty, assisted reproduction, and some hormone-dependent tumors.

\section{Disclosure Statement}

The authors declare no conflict of interest.

\section{References}

1. Sugiyama M, Imai A, Takahashi S, Hirano S, Furui T, et al. (2003) Advanced indications for gonadotropin-releasing hormone (GnRH) analogues in gynecological oncology (review). Int J Oncol 23 (2): 445-452.

2. Huirne J, Lambalk C (2001) Gonadotropin-releasing-hormone-receptor antagonists. Lancet 358 (9295): 1793-1803.

3. Broekmans F (1996) GnRH agonists and uterine leiomyomas. Hum Reprod 11(Suppl): 3-25.

4. Kumar P, Sharma A (2014) Gonadotropin-releasing hormone analogs Understanding advantages and limitations. J Hum Reprod Sci 7(3):170174.

\section{ISSN: 2574-1241}

DOI: 10.26717/BJSTR.2019.18.003169

Atsushi Imai. Biomed J Sci \& Tech Res

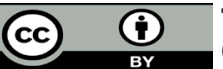

This work is licensed under Creative

Commons Attribution 4.0 License

Submission Link: https://biomedres.us/submit-manuscript.php
5. Jiang J, Gao S, Xu J (2018) Efficacy and Safety of gonadotropin-releasing hormone (GnRH) Agonists Triptorelin Acetate and Cetrorelix Acetate in Assisted Reproduction. Med Sci Monit 24: 7996-8000.

6. Tur Kaspa I, Ezcurra D (2009) GnRH antagonist, cetrorelix, for pituitary suppression in modern, patient-friendly assisted reproductive technology. Expert Opin Drug Metab Toxicol 5(10): 1323-1336.

7. Beguería R, García D, Vassena R, RodríguezA(2019) Medroxyprogesterone acetate versus ganirelix in oocyte donation: a randomized controlled trial. Hum Reprod 34(5): 872-880.

8. Frattarelli J, Hillensjö T, Broekmans F, Witjes H, Gordon K, et al. (2013) Clinical impact of LH rises prior to and during ganirelix treatment started on day 5 or on day 6 of ovarian stimulation. Reprod Biol Endocrinol 2013: $11: 90$.

9. Miyazawa Y, Sekine Y, Syuto T, Nomura M, Koike H, et al. (2017) A gonadotropin-releasing hormone antagonist reduces serum adrenal androgen levels in prostate cancer patients. BMC Urol 17(1):70.

10. Tokiwa S, Shimmura H, Nomura S, Watanabe R, Kurita M, et al. (2017) Degarelix treatment is compatible with diabetes and antithrombotic therapy in patients with prostate cancer. Res Rep Urol 9: 225-232.

11. Markham A Relugolix (2019) First global approval. Drugs 79(6): 675679

12. Nakata D, Masaki T, Tanaka A, Yoshimatsu M, Akinaga Y, et al. (2014) Suppression of the hypothalamic-pituitary-gonadal axis by TAK385 (relugolix), a novel, investigational, orally active, small molecule gonadotropin-releasing hormone (GnRH) antagonist: studies in human GnRH receptor knock-in mice. Eur J Pharmacol 723: 167-174.

13. Kittai A, Blank J, Graff J (2018) Gonadotropin-releasing hormone antagonists in prostate cancer. Oncology (Williston Park) 32 (12):604606

14. Osuga Y, Enya K, Kudou K, Tanimoto M, Hoshiai H (2019) Oral gonadotropin-releasing hormone antagonist relugolix compared with leuprorelin injections for uterine leiomyomas: a randomized controlled trial. Obstet Gynecol 133(3):423-433.

15. MacLean D, Shi H, Faessel H, Saad F (2015) Medical castration using the investigational oral GnRH antagonist TAK-385 (relugolix): phase 1 study in healthy males. J Clin Endocrinol Metab 100(12):4579-4587.

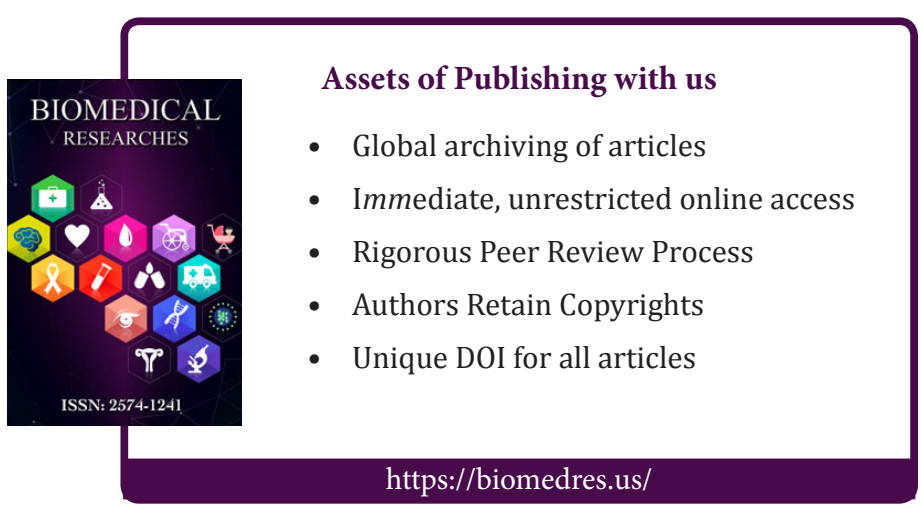

